\title{
MEDICINES SOLD WITHOUT A PRESCRIPTION \\ WITH A PLANT COMPONENT APPLIED AMONG CHILDREN DURING THE COVID-19 PANDEMIC
}

\section{BOZHIDARKA RADOSLAVOVA HADZHIEVA ${ }^{1}$, VALENTINA BOYANOVA PETKOVA ${ }^{2 *}$, and MILEN VENTCISLAVOV DIMITROV ${ }^{3}$}

\author{
${ }^{1}$ Medical College, Medical University - Plovdiv, 15a Vasil Aprilov Blvd., \\ Plovdiv 4002, Bulgaria, \\ ${ }^{2}$ Department of Social Pharmacy, Faculty of Pharmacy, Medical University - Sofia, 2 Dunav St., \\ Sofia 1000, Bulgaria \\ ${ }^{3}$ Department of Pharmaceutical Technology and Biopharmacy, Faculty of Pharmacy, \\ Medical University - Sofia, 2 Dunav St., Sofia 1000, Bulgaria
}

\begin{abstract}
The interest in the practical use of herbal substances for medical purposes is growing worldwide. The herbal medicines can be applied as a supplement not only to restore the physiological functions but also to treat specific conditions such as - dyspepsia; hepatic and biliary diseases; prevent and modify cardiovascular diseases; treat infectious diseases. They are among the pharmaceutical products preferred by parents and pediatricians. In January 2020, the World Health Organization (WHO) declared the spread of the new coronavirus - a situation with a global impact. During the last year, there have been some publications describing the use of Chinese herbal preparations for the prevention and prophylaxis of COVID-19. There is information about the use of pharmaceuticals to treat infectious diseases and fever but real evidence for their impact on the SARS-CoV-2 virus is still insufficient. Therefore, the purpose of this study is to establish how many of the medicines sold without a prescription containing a plant component are used among very young children in Bulgaria and if these phytoproducts can be used to treat pediatric patients with COVID-19.
\end{abstract}

Keywords: medicines, herbal, children, COVID-19, phytotherapy

Herbal medicines are a widely accepted source of treatment in both developed and developing countries $(1,2)$. The plants are used for thousands of years and are still regarded as the most important source of new potential therapeutic preparations (3).

According to the literature, almost $50 \%$ of all prescribed medicines in industrially developed countries are obtained or synthesized from natural products, as the sources used are of animal, marine, plant, and microbial origin. (4).

Plants have been used to obtain pure substances (or natural products) applied in modern medical practice. Other compounds are potentially useful or manifest toxic effects.

The compounds of plant origin have a long history of clinical use, better tolerance, and admission by the patient. Plant sources have yielded some important modern therapeutic means such as Aspirin (Salix spp L.) and Taxol (Taxus baccata L.) (5).
Herbal medicines also play an increasingly important role in global health care, conquering new and expanding markets as healthy foods and preventive medicines $(6,7)$.

In addition, the use of traditional medicines increases when conventional medicine proves to be ineffective in the treatment of patients, for example in the case of advanced cancer and some infectious diseases (8).

From a historical perspective, the use of herbal medicines plays an important role in a number of diseases, including infectious. Some studies on the application of phytotherapy in the treatment of coronavirus (SARS-CoV-2) have shown satisfactory results. They support the idea that phytotherapy has a beneficial effect on the treatment and prophylaxis of epidemic diseases.

A case of severe pneumonia with an unidentified cause, later identified as severe acute respiratory

* Corresponding author: e-mail: petkovav1972@yahoo.com 
syndrome coronavirus 2 (SARS-CoV-2) was first registered in December 2019 in Wuhan, the capital of the Hubei Province, China $(9,10)$.

According to the evidence, children of all ages may be affected by COVID-19. Studies, conducted in China and USA, show that children under 12 and 14 years of age are affected more rarely than adults $(11,12)$.

Some studies on pediatric patients infected with SARS-CoV-2 have shown the lack of specificity regarding the COVID-19 symptoms and their relative share as asymptomatic patients (13).

A study conducted at a hospital in Wuhan shows that the most common symptoms of COVID-19 include fever (100\%), tachypnea (75\%), cough (75\%), sputum secretion (50\%), and nausea/vomiting (50\%) (14).

In summary, fever, cough, and tachypnea are the most common clinical symptoms of COVID-19 among children (15). The first clinical manifestation of COVID-19 in some patients is nausea/vomiting. According to the data collected not only the lungs but also the gastrointestinal tract can be attacked by SARS-CoV-2. The successor of SARS-CoV-2 is the Angiotensin-converting enzyme (ACE2), which acts as a trigger to the infection and is significantly manifested in the gastrointestinal epithelium and may cause nausea/vomiting (16). Diarrhea and vomiting are some of the symptoms of COVID-19 which have been reported in a smaller percentage of pediatric patients (11). Although a study reports a case of a 16-month-old child (a girl) with confirmed COVID-19 with gastroenteritis, without any other symptoms of COVID-19. These symptoms are unusual in the absence of other more common symptoms such as fever, cough, sore throat, sneezing, myalgia, and fatigue (17).

We need to consider that the pandemic will last over the seasons and will coincide with the peak periods of the flu, as a result of which it will be difficult to distinguish the cases of pediatric patients with COVID-19 from those with flu (13).

Clinical evidence has been established of a positive effect resulting from the use of herbal medicines in the treatment of COVID-19. There is no proven therapy for COVID-19 and the actual efficacy and safety of the current therapeutic approaches will need additional control when sufficient clinical data are available $(18,19)$.

Therefore, the purpose of this study is to establish how many of the medicines with a plant component dispensed without a prescription are applied among children at the earliest age and if these phytoproducts can be used in the treatment of pediatric patients with COVID-19.

\section{METHODS}

Document analysis has been used to examine the register of the Bulgarian Drug Agency of all the registered medicines sold without a prescription in Bulgaria. This study has been conducted on the grounds of data published on the Bulgarian Drug Agency website from $25^{\text {th }}$ January to $9^{\text {th }}$ September 2020. We conducted the study for a period of three months - from February to April 2020. The list of the medicines sold without a prescription in the Republic of Bulgaria is periodically updated and its latest update was made on 23.08.2021.

We have analyzed the medicines sold without a prescription based on the following inclusion criteria: the number of medicines sold without a prescription containing a plant component; the number of phytopharmaceuticals applied among the pediatric patients; the type of the plant material; phytopharmaceuticals having the potential to affect COVID-19 applied among pediatric patients. We have excluded the medicines sold without a prescription containing plant components that are used among adults over 18 years of age.

\section{RESULTS}

Based on the data obtained from the register of the Bulgarian Drug Agency, the number of the registered medicines sold without a prescription on $25^{\text {th }}$ January is 999 (20). We conducted a document analysis to study the brief description of the specified medicines and we established that 262 medicines sold without a prescription contain a plant component, which constitutes approximately $1 / 4$ of the total number of the registered medicines in Bulgaria (Fig. 1).

The number of medicines without a prescription containing plant components, which are applied among pediatric patients, is 198 . The studied medicines can be applied to children aged 0-18 years.

For the purposes of analysis, we have studied the number of the medicines appropriate for each age group: breastfeeding babies by the $28^{\text {th }}$ day; breastfeeding babies by the $12^{\text {th }}$ month; early childhood; pre-school period; school period; adolescence. The studied medicines with a plant component can be applied for different symptoms. The largest is the number of pharmaceuticals sold without a prescription which are applied among schoolchildren. They are used to relieve the symptoms of cold (cough, rhinitis), pain, and can be applied as antiviral, antiacid, and antiulcer agents, in case of hepatic diseases and others. 


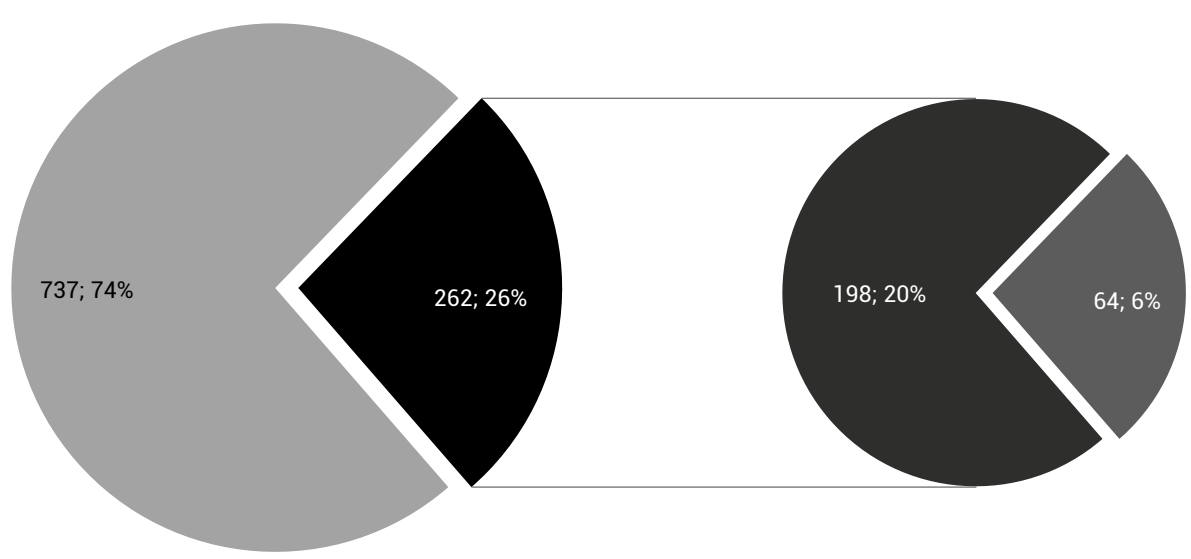

OTC contain synthetic substances registered on 25th January 2020

- OTC contain a plant component applied among the pediatric patients registered on 25th January 2020

OTC contain a plant component don't applied among the pediatric patients registered on 25th January 2020

Figure 1. The ratio of the medicines containing a plant component to the total number of the registered medicines sold without a prescription.

The number of the medicines with a plant component (indicated on the graph with a number (1)) and a combination of plant substances (indicated on the graph with a number (2)), which are applied among the studied children's age groups is 40 , which constitutes $20 \%$ of the medicines sold without a prescription among the pediatric patients and $4 \%$ of the total number of medicines included in the list of the Bulgarian Drug Agency (Fig. 2).
During the period of breastfeeding and early childhood, the medicines sold without a prescription contain mainly a plant-based active substance such as liquid extract of thyme roots (Thymi herba extractum fluidum), liquid extract of marshmallow roots (Althaea off. extractum fluidum), liquid extract of primula roots (Primulae radicis extractum liquidum), liquid extract of sage leaves (Salviae off. extractum fluidum), thick/dry extract of ivy

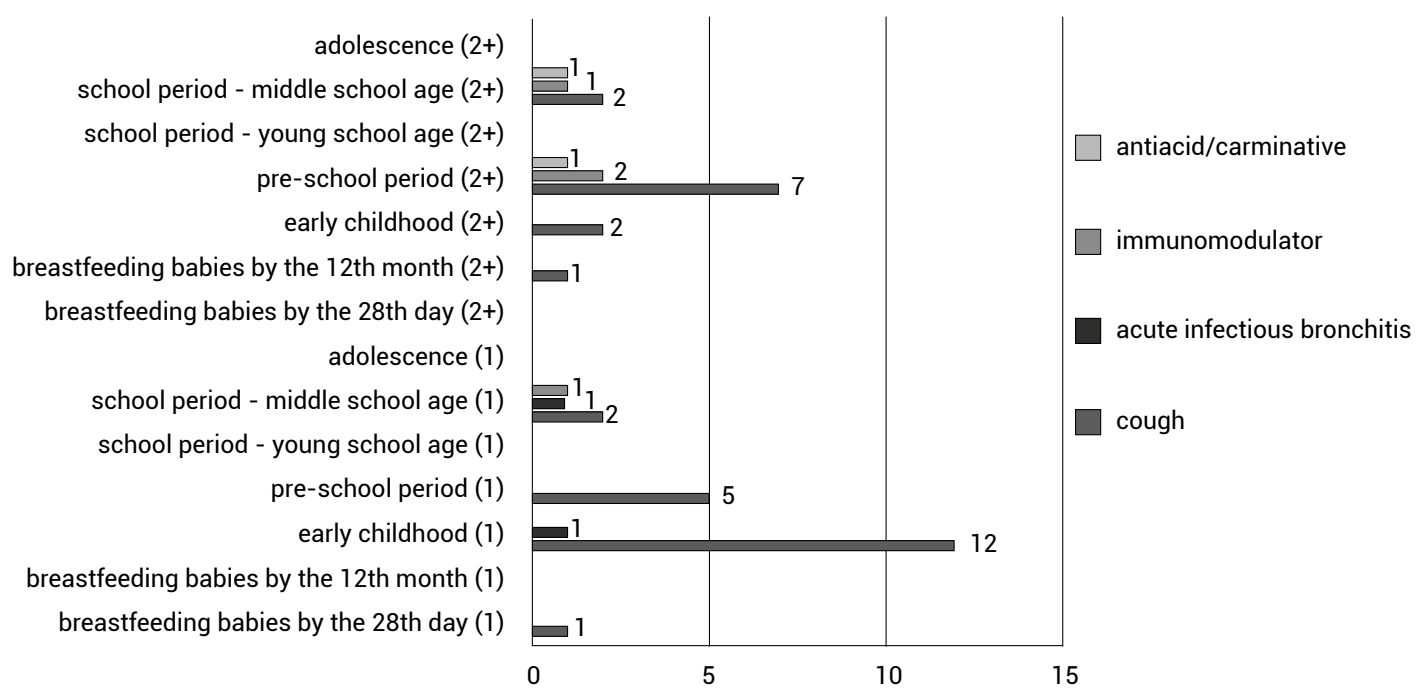

Figure 2. Allocation of the medicines without a prescription containing only a plant component among the pediatric patients based on the indications for applying *abbreviations in the diagram - explanation

\begin{tabular}{|c|c|}
\hline Designation in the diagram & Explanation \\
\hline (1) & $\begin{array}{l}\text { medicines containing one plant component applied among pediatric patients from } \\
\text { the specified age groups }\end{array}$ \\
\hline (2) & $\begin{array}{c}\text { medicines containing two and more plant components applied among pediatric patients } \\
\text { from the specified age groups }\end{array}$ \\
\hline
\end{tabular}




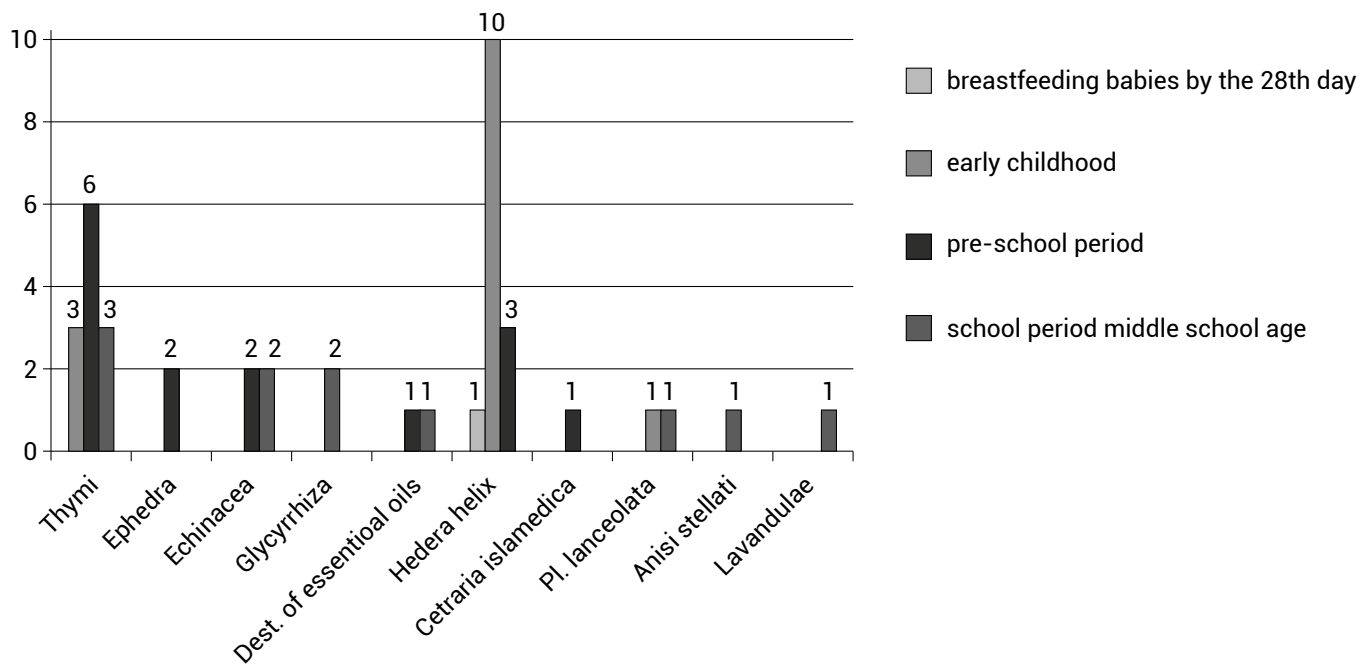

Figure 3. Medicines without a prescription containing plant components which are appropriate to be used for reducing the frequency and the intensity of the cough.

leaves (Hederae helicis folium extractum spissum/ siccum). The specified extracts contain biologically active substances - aromatic monoterpenes, slimy substances, triterpenoid saponins which cure symptoms such as cough, sore throat, husky voice (21).

Our study has established 12 plant-based medicines sold without prescription that contain Thymi herba extractum fluidum as a separate substance or most often in combination with Althaea off. extractum fluidum/Primulae radicis extractum liquidum, which are applied among the specified age groups. The phytoproducts containing $H$. helicis folium extractum spissum/siccum are 14, as one of them is applied among breastfed babies (Fig. 3).

\section{DISCUSSION}

The studied herbal medicines can be used to reduce the frequency and the intensity of the cough during infection with the virus of SARS-CoV-2. Both adult patients and children show good tolerance to $H$. helix $\mathrm{L}$. but the evidence regarding its use is still insufficient to recommend its application in the treatment or prophylaxis of COVID-19. Providing proof will justify future studies for a better understanding of the application of H. helix $\mathrm{L}$. in the case of a coronavirus infection (22).

Our study has established two products containing Glycyrrhizae radix et rhizome which are used in case of functional and motility-related gastrointestinal diseases, including the treatment of complaints in the case of a gastric mucosa inflammation.
The products with an immunostimulating activity that can be applied among pre-school children are 2 in the list and contain Echinacea purpurea herbae succus recens. Examples of medicinal plants with immunostimulating effects and antiviral activity are Echinacea purpurea (L.) Moench, Andrographis paniculata (Burm. f.) Nees, Sambucus nigra L., Allim sativum L. propolis is a raw material that has proven its antiviral effect. The Echinacea genus is endemic in Canada and North America. It was initially described by McGregor, as four types, and eight varieties are known at present (23). The Echinacea purpurea extract is traditionally used in North America to treat different types of infections and wounds and later they were widely used as a herbal medicine worldwide. The medicines containing Echinacea (Echinacea angustifolia DC., E. purpurea (L.) Moench и E. pallida (Nutt.) Nutt.) are most commonly used to fight viral infections, including flu and ordinary cold $(24,25)$. The products containing Echinacea can be used in the form of a liquid extract obtained from a fresh plant or a dried plant substance from roots and/or root systems. The phytochemical composition and the concentration of the active components of Echinacea vary depending on the part of the plant from which the plant substance has been obtained $(26,27)$. The root extract of $E$. purpurea (L.) Moench contains a powerful watersoluble antiviral ingredient which can deactivate the herpes simplex virus (HSV) and the flu virus (FV) (28), but not the rhinovirus (RV). The root extract of E. pallida var. angustifolia manifests a significant anti-rhinovirus activity, probably due to the presence of one or more alkylamides which are contained in preparations with an ethanol solvent (29). 
The admission of products containing Echinacea when detecting initial symptoms of an acute respiratory infection (ARI) can reduce the burden or the duration of the disease (30).

A synoptic survey states that plant preparations of Echinacea manifest an antiviral activity regardless of the immunomodulating functions and are used to treat the flu, the Respiratory syncytial virus, the parainfluenza viruses, and also the major pathogenic coronaviruses, SARS-CoV and MERS-CoV. The antiviral activity is probably manifested during the extracellular stage, prior to the entry of the virus and during the release of the virus but the exact mechanisms remain unclear. It is assumed that the preparations modify the viral components, probably the membrane and the membrane protein, as they seem to be particularly effective in the case of enveloped viruses. The activity mainly depends on the part of the plant from which the plant material has been obtained as well as the type of the extract but the $E$. purpurea (L.) Moench preparations give us hope for a possible adjuvant therapy or a supplement for fighting SARS-CoV2 (31).

The medicinal plant Andrographis paniculata (Burm. f.) Nees (Acanthaceae) has been widely used in many countries (32). The basic biologically active compounds extracted from $A$. paniculata are: diterpenoids, flavonoids, and polyphenols but the different bioactive properties are mainly due to the presence of andrographolide. (33) A. paniculata (Brum. f.) Nees is used in medical practice as an anti-inflammatory, hepatoprotective, antiviral, antioxidant, and immunostimulating plant medicine (34-36). An examination was conducted of the antiviral and the immunostimulating properties of an ethanol extract of $A$. paniculata (Brum. f.) Nees which was analyzed using high-performance liquid chromatography in order to determine the content of active compounds, mainly andrographolide. The results from the examination have shown that the ethanol extract of $A$. paniculata (Brum. f.) Nees stimulates the proliferation of lymphocyte cells in low concentration (37). In addition to its anti-inflammatory effects, the andrographolide also manifests immunomodulating activities resulting from the increase of the cytotoxic $\mathrm{T}$ cells, the natural killer cells, the phagocytose, and the antibody-dependent cell-mediated cytotoxicity (ADCC) (38).

Sambucus nigra L., known as an elder, black elder, and European elder is a plant that has a long history. It is becoming more popular due to its antiviral and immunomodulating effects (39, 40). Krawitz et al have shown in their study that the standardized liquid elder extract possesses antimicrobial properties regarding gram-positive Streptococcus pyogenes bacteria and streptococci from the $\mathrm{C}$ and $\mathrm{G}$ groups as well as regarding the gram-negative bacteria Branhamella catarrhalis in liquid cultures. The liquid extract has an inhibitory effect on the spread of human pathogenic flu viruses (41). The elder extract is effective in the treatment of flu, by manifesting numerous ways for therapeutic activity against the flu infection (42). Some compounds contained in the black elder can be toxic, therefore it is necessary to perform strict control and conduct additional tests to confirm its safety (43). Christie Chen et al. have assessed the impact of treatments involving $S$. nigra extract on the replication of the pathogenic avian coronavirus (Infectious bronchitis virus IBV). The $S$. nigra extract destroys the IBV structure in the early stage of the infectious process, most probably by making it uninfectious. It is possible that the polyphenol content, which is present in the fruits of $S$. nigra L. (44), contributes to this inhibition because the plants containing high concentrations of polyphenols manifest antiviral properties. The researchers assume that the $S$. nigra extract may have an extensive antiviral effect on other viruses (45).

We need to consider the fact that the evidence of integrative strategies for prevention and treatment of COVID-19, based on the clinical experience, is still insufficient. (46)

The medicinal plants and their combinations, which are recommended for the treatment of COVID-19 among children are fewer compared to those used among adult patients (47).

A synoptic survey states that Glycyrrhizae radix et rhizome is a medicinal plant with the highest frequency of use among adult patients with COVID-19 regardless of the stage of the disease. There are numerous studies reporting that Glycyrrhizae radix et rhizome inhibits the attachment of the virus, its entry, and replication, which is used mainly to fight COVID-19 $(48,49)$.

\section{CONCLUSIONS}

The pharmaceutical companies are facing the challenge of creating innovative medicinal forms intended for children, whose composition will include plant components that have shown antiviral activity.

Despite the existing statements that the traditional herbal medicines are effective in the prevention of COVID-19 and the unwanted effects are minimum, the evidence is still insufficient. It is necessary to conduct an in-depth study of herbal 
materials containing active components which have manifested an antiviral activity and also the mechanisms of this activity. The development of therapeutic schemes of effective phytotherapy and appropriate medicinal forms for the pediatric population is crucial in the prevention and prophylaxis of the SARS-CoV-2 virus.

\section{REFERENCES}

1. Azhar I., Basheer E., Javaid Z., Sohail K.: Acta Pol. Pharm. 74, 1321 (2017).

2. Sahoo N., Manchikanti P., Dey S.: Fitoterapia 81, 462 (2010).

3. Bernardini S., Tiezzi A., Laghezza Masci V., Ovidi E.: Nat. Prod. Res. 32, 1926 (2017).

4. Lahlou M.: Journal P.P. 4, 17 (2013).

5. Veeresham C.: J. Adv. Pharm. Technol. Res. 3, 200 (2012).

6. Kilova K.: Knowl. Int. J. 43, 859 (2020).

7. Kilova K., Uzunova S.: Acta Med. Bulg. 47, 63 (2020).

8. Benzie I.F.F., Wachtel-Galor S.: in Herbal Medicine: Biomolecular and Clinical Aspects. 2nd ed., Benzie I., Wachtel-Galor S. Eds., Ch 1, CRC Press, Taylor and Francis, Boca Raton (FL) (2011).

9. Singhal T.: Ind. J. Ped. 87, 281 (2020).

10. Chauhan S.: Biomed. J. 43, 334 (2020).

11. Lu X, Zhang L, Du H, Zhang J, Li YY, Qu J, Zhang W et al.: N. Engl. J. Med. 382, 1663 (2020).

12. Bialek S., Gierke R., Hughes M., McNamara L., Pilishvili T., Skoff T.: Morb. Mortal. Wkly. Rep. 69, 422 (2020).

13. Assaker R., Colas A.E.: BJA 125, e330 (2020).

14. Sun D., Li H., Lu X.X., Xiao H., Ren J., et al.: World J. Pediatr. 16, 251 (2020).

15. Gholami A., Roholallah H., Khorshidi A., Borji M., Kafashian M., et al.: Int. J. Pediatr. 8, 12177 (2020).

16. Zhang T., Liu D., Tian D., Xia L.: J. Microb. Imm. Inf. 54, 541 (2020).

17. Moradveisi B., Ataee P., Ghaffarieh A., Karimi A., Fattahi N., Nasseri K.: Adv. Biomed. Res. 9, 35 (2020).

18. Silveira D., Prieto-Garcia J.M., Boylan F., Estrada O., Fonseca-Bazzo Y.M.: et al.: Front. Pharmacol. 11, 220 pages (2020).

19. Scavone C., Brusco S., Bertini M., Sportiello L., Rafaniello C., et al.: Br. J. Pharmacol. 177, 4813 (2020).
20. https://www.bda.bg/images/stories/documents/ new_registered/202104/OTC (accessed on 15.12.2020).

21. Du Y., Wolf I.K., Zhuang W., Bodemann S., Knöss W., Knopf H.: BMC Compl. Altern. Med. 14, 41 pages (2014).

22. Barnes L. A., Leach M., Anheyer D., Brown D., Carè J., et al.: Adv. Integr. Med. 7, 222 (2020).

23. Flagel L.E., Rapp R.A., Grover C.E., Widrlechner M.P., Hawkins J., et al.: Amer. J. Bot. 95, 756 (2008).

24. Hudson J.B.: J. Biomed. Biotechnol. 2012, 65 pages (2012).

25. Vimalanathan S., Kang L., Amiguet V.T., Livesey J., Arnason J.T., Hudson J.: Pharm. Biol. 43, 740 (2005).

26. Foster B.C., Drouin C., Krantis A., Panahi M., Franovic A., Burczynski F.J.: J. Compl. Integr. Med. 2 (2005).

27. Vohra S., Adams D., Hudson J.B., Moore J.A., Vimalanathan S., et al.: Can. J. Physiol. Pharmacol. 87, 371 (2009).

28. Saeidnia S., Manayi A., Vazirian M.: Pharmacogn. Rev. 9, 63 (2015).

29. Hudson J., Vimalanathan S., Kang L., Amiguet V.T., Livesey J., Arnason J.T.: Pharm. Biol. 43, 790 (2005).

30. Aucoin M., Cooley K., Saunders P.R., Carè J., Anheyer D., et al.: Adv. Integr. Med. 7, 203 (2020).

31. Kembuan G., Lie W.,Tumimomor A.: Int. J. Med. Rev. Case Rep. 4, 13 (2020).

32. Hossain M.S., Urbi Z., Sule A., Hafizur Rahman K.M.: ScientificWorldJournal 2014, 91 pages (2014).

33. Chao W.W., Lin B.F.: Chin. Med. 5, 17 (2010).

34. Singha P.K., Roy S., Dey S.: Fitoterapia 74, 692 (2003).

35. Jayakumar T., Hsieh C.Y., Lee J.J., Sheu J.R.: Evid. Based Complement. Alternat. Med. 2013, 60 pages (2013).

36. Okhuarobo A., Falodun J. E., Erharuyi O., Imieje V., Falodun A., Langer P.: Asian Pac. J. Trop. Dis. 4, 213 (2014).

37. Churiyah, Pongtuluran O.B., Rofaani E., Tarwadi: Hayati 22, 67 (2015).

38. Gupta S., Mishra K.P., Ganju L.: Arch. Virol. 162, 611 (2016).

39. Ağalar H.: in Nonvitamin and Nonmineral Nutritional Supplements compiles comprehensive, Nabavi S., Silva A., Eds.: U. K. Acad. Press, Ch. 3.14, 211 London 2019.

40. Porter R., Bode R.: Phytother. Res. 31, 533 (2017). 
41. Krawitz C., Mraheil M.A., Stein M., Imirzalioglu C., Domann E., Pleschka S., Hain T.: BMC Compl. Altern. Med. 11, 11 (2011).

42. Torabian G., Valtchev P., Adil Q., Dehghani F.: J. Funct. Foods 54, 353 (2019).

43. Vlachojannis J.E., Cameron M., Chrubasik S.: Phytother. Res 24, 1 (2010).

44. Lee J., Finn C.E.: J. Sci. Food. Agric. 87, 2665 (2007)

45. Chen C., Zuckerman D.M., Brantley S., Sharpe M., Childress K., et al.: BMC Vet. Res. 10, 24 (2014).
46. Alschuler L., Weil A., Horwitz R., Stamets P., Chiasson A. M., et al.: Explore (N.Y.) 16, 354 (2020).

47. Ang L., Lee H. W., Kim A., Lee J. A., Zhang J., Lee M. S.: Complement. Ther Clin. Pract. 3918 pages (2020).

48. Ang L., Lee H.W., Choi J.Y., Zhang J., Lee M.S.: Integr. Med. Res. 9, 24 pages (2020).

49. Ali I., Alharbi O.M.L.: Sci. Total Environ. 728, 30 pages $(2020)$.

(C) 2021 by Polish Pharmaceutical Society. This is an open-access article under the CC BY NC license (https://creativecommons.org/licenses/by-nc/4.0/). 